\title{
Compare the effect of noninvasive ventilation and tracheotomy in critically ill mechanically ventilated neurosurgical patients: a retrospective observe cohort study
}

\author{
Meiling Dong, Yongfang Zhou, Jing Yang, Jie Yang, Xuelian Liao and Yan Kang* (i)
}

\begin{abstract}
Objective: Patients with severe brain injury is usual at high risk of extubation failure, despite of those with no/ minor primary respiratory problem, majority of them still needs long term respiratory support and has severe pulmonary complications. This retrospective study aimed to compare the effect of noninvasive ventilation (NIV) and tracheotomy on the prognosis in critically ill mechanically ventilated neurosurgical patients.

Methods: This is a single center, retrospective observe cohort study. Postoperative patients with brain injury consecutively admitted to ICU from November 1st, 2015 through February 28th, 2017, who had received invasive mechanical ventilation more than $48 \mathrm{~h}$ were screened, those who received NIV or tracheotomy procedure, meanwhile with Glasgow Coma Scale (GCS) score between 8 and 13 points before using NIV or undergoing tracheotomy, were retrospectively included in this study. The demographic data and clinical main outcomes such as ICU and hospital mortality, time of mechanical ventilation, length of ICU and hospital were collected. The primary outcome was the incidence of postoperative pulmonary infection between two groups.

Results: 77 patients were included in this study. 33 patients received NIV, and 44 patients received tracheotomy through the ICU duration. The incidence of postoperative pulmonary infection in NIV group was significantly lower than that in tracheotomy group (54.5\% VS 84.1\%, $P<0.05)$, Application of NIV was associated with shorter duration of invasive mechanical ventilation ([median $123.0 \mathrm{~h}$ VS $195.0 \mathrm{~h}, P<0.05$ ). Moreover, GCS score at ICU discharge, as well as the difference of GCS score between at admission to ICU and ICU discharge were also better than the tracheotomy group $(P<0.001)$.

Conclusion: Compared with tracheotomy, use of NIV after extubation in critically ill mechanically ventilated neurosurgical patients may be associated with lower incidence of postoperative pulmonary infection, shorter duration of invasive mechanical ventilation and better improvement in brain function. Further studies need to verify the effect of NIV in this kind of patients.
\end{abstract}

Keywords: Noninvasive ventilation, Brain injury, Tracheotomy, Postoperative pulmonary infection

* Correspondence: Kangyan@scu.edu.cn

Department of critical care medicine, West China Hospital of Sichuan

University, Sichuan Province, Chengdu 610041, China

(c) The Author(s). 2019 Open Access This article is distributed under the terms of the Creative Commons Attribution 4.0 International License (http://creativecommons.org/licenses/by/4.0/), which permits unrestricted use, distribution, and reproduction in any medium, provided you give appropriate credit to the original author(s) and the source, provide a link to the Creative Commons license, and indicate if changes were made. The Creative Commons Public Domain Dedication waiver (http://creativecommons.org/publicdomain/zero/1.0/) applies to the data made available in this article, unless otherwise stated. 


\section{Introduction}

Brain injury is a growing problem of public health and social economy in the world. In United States, about 235,000 patients are admitted to hospital every year because of traumatic brain injury, and the annual death toll is about 50,000. The total cost of hospitalization due to traumatic brain injury in 2010 amounted $\$ 21$ billion to 400 million $[1,2]$. In China, the incidence of traumatic brain injury in the age of over 65 years has increased by $7.78 \%$ annually, with an average hospitalization cost of $\$ 795$ and a fatality rate of $9.38 \%$ [3]. In order to maintain respiration, optimize oxygenation and protect airway, patients with brain injury usually need Mechanical Ventilation (MV) in ICU. The vast majority of brain injury patients without respiratory problem, when the patient acute physiological disorder has improved, most patients can wean from MV as soon as possible. However, more than $20 \%$ of patients still need ventilator support after 21 days [4]. These patients may need tracheotomy or noninvasive ventilation (NIV) for further treatment. Previous studies have shown that long-term mechanical ventilation were associated with a lot of pulmonary complications in patients with severe brain injury, such as ventilator-associated lung injury, pulmonary infection, diaphragm dysfunction, pulmonary embolism and so on, and increased the mortality of disease [5]. Relevant studies also demonstrated that, in brain-injured patients,the incidence of pulmonary infection was $20 \%$, the rate of reintubation caused by extubation failure was from 10 to $15 \%$, and the incidence of pneumonia after extubation failure was as high as $85 \%$ [6-8].

NIV has become a common alternative to invasive ventilation at present, several studies have shown that NIV weaning strategy was superior to invasive weaning strategy in hypercapnic respiratory failure patients, and it could significantly reduce the re-intubation rate, the incidence of ventilator associated pneumonia (VAP), duration of mechanical ventilation, and the ICU and hospital length of stay [9-12]. But there were few studies and literatures demonstrated the benefits of NIV in acute hypoxemic respiratory failure, especially in the brain injury patients. Lack of research has caused considerable confusion to clinical workers: could NIV improve the prognosis of patients who accepted brain injury surgery? Therefore, we designed this retrospective study to explore the impact of NIV on the prognosis of patients who accepted brain injury surgery compared with tracheotomy.

\section{Materials and methods}

\section{Patients}

This was a retrospective, observe cohort study of data from patients after brain injury surgery at the intensive care unit (ICU) of West China Hospital, Sichuan
University, Chengdu, Sichuan province, China, between November 1st, 2015 and February 28th, 2017. The ethics committee of West China Hospital approved this study. Critically ill mechanically ventilated neurosurgical patients admitted to our ICU will be managed according to different disease protocols, these protocols are based on guidelines and the clinical experience of physicians. Patients older than 18 and less than 85, who still needed invasive mechanical ventilation longer than $48 \mathrm{~h}$ after neurosurgery, were recruited in our study. Patients were excluded if they were pregnant, without NIV and tracheotomy treatment during total ICU stay, with Glasgow Coma Scale (GCS) score before NIV or tracheotomy less than 8 and more than 12 points, and with multiple organ failure, hemodynamic instability and tracheostomy prior to ICU admission.

\section{Methods}

According to inclusion and exclusion criteria, the demographic data and clinical main outcomes of selected patients were collected. The data included demographic characteristics of enrolled patients, information about perioperative period, and other basic information related to respiratory system and nervous system from ICU admission to ICU discharge or maximum of 28 days. Of which, the respiratory system data included daily blood gas, daily ventilator parameters, daily major respiratory events (such as extubation, wearing NIV, tracheotomy, changing cannula, etc.), daily pulmonary complications, daily lung imaging, daily clinical pulmonary infection score (CPIS) and so on. The nervous system data included the occurrence of cranial complications, intracranial pressure, daily GCS score and so on. According to whether NIV or tracheotomy was performed after invasive mechanical ventilation during ICU stay, the patients were divided into NIV group and tracheotomy group.

The primary outcome in this study was the incidence of postoperative pulmonary infection in patient ICU stay. Simplified version of the clinical pulmonary infection score (sCPIS) was used to evaluate the pulmonary infection of enrolled patients [13]. The sCPIS contains five variables and the calculation is displayed on Table 1. If the total points is greater than or equal to 6 points, we considered a postoperative pulmonary infection [14, 15]. The secondary outcomes were the incidence of other pulmonary complications, re-intubation rate, duration of mechanical ventilation, and the length of ICU stay and hospital stay.

\section{Statistical analysis}

SPSS22.0 was used for statistical analysis of data in our study. Continuous variables with a normal distribution were expressed as the mean \pm standard deviation, and inter-group comparison was analyzed by the Student's 
Table 1 Simplified version of the clinical pulmonary infection score (sCPIS)

\begin{tabular}{lll}
\hline Variables & Value & Points \\
\hline Chest radiograph & No infiltrate & 0 \\
& Patchy or diffuse infiltrate & 1 \\
& Localized infiltrate & 2 \\
Tracheal secretions & Few & 0 \\
& Moderate & 1 \\
& Large & 2 \\
Temperature ${ }^{\circ} \mathrm{C}$ & Purulent & +1 \\
& $\geq 36.5$ and $\leq 38.4$ & 0 \\
Oxygenation $\mathrm{PaO}_{2} / \mathrm{FIO}_{2}, \mathrm{mmHg}^{2}$ & $>240$ or presence of ARDS & 0 \\
& $\leq 240$ and absence of ARDS & 2 \\
Blood leukocytes per $\mathrm{mm}^{3}$ & $\geq 4000$ and $\leq 11,000$ & 0 \\
& $<4000$ or $>11,000$ & 1
\end{tabular}

ARDS acute respiratory distress syndrome. Total points for SCPIS varied from 1 to 10 points t test. Continuous variables with non-normal distribution were expressed as the median and interquartile ranges (IQR), and their differences were compared with the Mann-Whitney U test. Dichotomous or nominal categorical variables were expressed as percentages, and analyzed by either the Pearson Chi-square or Fisher's exact test. A two-sided $P$ value of $<0.05$ was considered to statistical significance.

\section{Results}

A total of 1278 patients admitted to SICU and NICU in our hospital from November 2015 to February 2017 were screened. 77 patients were enrolled in this study finally, including 33 patients who had only used NIV (NIV group) and 44 patients who had only undergone tracheotomy (tracheotomy group) after invasive mechanical ventilation.

Table 2 showed the patient baseline characteristics between two groups. There was no difference in any baseline characteristics between two groups $(P>0.05)$. The level of consciousness and the criticality of the patient were similar between two groups, with no significant differences of APACHE II score and GCS score before NIV or tracheotomy were observed between two groups.

Table 2 Baseline characteristics of patients

\begin{tabular}{|c|c|c|c|}
\hline Characteristic & $\mathrm{NIV}(n=33)$ & $\operatorname{Tracheotomy}(n=44)$ & $P$ value \\
\hline Age, years (Median, IQR) & $57(48-64)$ & $61.5(50.5-66.7)$ & 0.187 \\
\hline Gender, male, n (\%) & $15(45.5 \%)$ & $22(50.0 \%)$ & 0.693 \\
\hline Smoke, n (\%) & $9(27.3 \%)$ & $10(22.7 \%)$ & 0.647 \\
\hline Body Mass Index (mean \pm SD) & $23.74 \pm 3.53$ & $23.17 \pm 2.85$ & 0.434 \\
\hline \multicolumn{4}{|l|}{ Basic disease, n (\%) } \\
\hline COPD & $4(12.1 \%)$ & $3(6.8 \%)$ & 0.454 \\
\hline Hypertension & $17(51.5 \%)$ & $22(50.0 \%)$ & 0.895 \\
\hline Cerebrovascular events & $7(21.2 \%)$ & $6(13.6 \%)$ & 0.38 \\
\hline \multicolumn{4}{|l|}{ Basic condition before operation, n (\%) } \\
\hline Vomit & $12(36.4 \%)$ & $13(29.5 \%)$ & 0.527 \\
\hline Aspiration & $4(12.1 \%)$ & $8(18.2 \%)$ & 0.468 \\
\hline Epilepsy & $0(0.0 \%)$ & $2(4.5 \%)$ & 0.504 \\
\hline pulmonary infection & $13(39.4 \%)$ & $10(22.7 \%)$ & 0.114 \\
\hline coma before operation, n (\%) & $10(30.3 \%)$ & $19(43.2 \%)$ & 0.248 \\
\hline Emergency operation, n (\%) & $16(48.5 \%)$ & $23(52.3 \%)$ & 0.644 \\
\hline APACHE II score at ICU admission (Median, IQR) & $17.0(15.5-20.0)$ & $17.5(16.0-20.0)$ & 0.623 \\
\hline GCS score at ICU admission (Median, IQR) & $9.0(8.0-9.5)$ & $9.0(8.0-9.0)$ & 0.107 \\
\hline Coma after operation, n (\%) & $28(84.8 \%)$ & $46(76.7 \%)$ & 0.349 \\
\hline GCS score before NIV or tracheotomy (Median, IQR) & $9.0(9.0-10.5)$ & $8.0(8.0-10.0)$ & 0.115 \\
\hline ICU duration before NIV or tracheotomy, days (Median, IQR) & $5.0(3.0-7.5)$ & $4.0(3.0-7.0)$ & 0.104 \\
\hline IMV time before NIV or tracheotomy, hours (Median, IQR) & $115(61.0-178.5)$ & $100(63.13-164.5)$ & 0.607 \\
\hline
\end{tabular}

Data are expressed as the mean \pm standard deviation, and as the median and interquartile ranges (IQR), or percentages. SD standard deviation, COPD Chronic Obstructive Pulmonary Disease, APACHE I/ Acute Physiology and Chronic Health Evaluation; ICU intensive care unit, GCS Glasgow Coma Scale, IMV Invasive mechanical ventilation 
Study outcomes are showed in Table 3. The incidence of postoperative pulmonary infection in NIV group was lower than tracheotomy group [54.5\% vs.84.1\%, $P<0.05$ ] (Table 3 and Fig. 1), and the duration of invasive mechanical ventilation was shorter than tracheotomy $\operatorname{group}(P<0.05)$. In addition, the length of ICU and hospital stay in the NIV group were also shorter than tracheotomy group. And we found that NIV group showed a higher GCS score at discharge ICU and GCS score difference between admission and discharge ICU. This suggested that NIV may accelerate the recovery of consciousness in brain injury surgery patients.

\section{Discussion}

Our study demonstrated that NIV was associated with lower postoperative pulmonary infection incidence, shorter duration of invasive mechanical ventilation, better level of consciousness at ICU discharge, compared with tracheotomy.

When patients do not meet the MV withdrawal criteria, some medical workers may choose tracheotomy and some may choose early NIV intervention. There still are some controversies about the possible benefits of NIV compared with tracheotomy. The strength of mechanical ventilation support is generally low in patients with brain injury, however, due to disturbance of consciousness or damage of brain stem, airway protective reflexes such as cough and swallow weakened or disappeared, and artificial airway continue to be needed to maintain airway unobstructed [16]. But for patients without other mechanical ventilation indications, people who need respiratory support and artificial airway may be different. For patients who only need respiratory support, the complications caused by artificial airway cannot be ignored [17-19]. Early and timely application of NIV can reduce complications of artificial airway, avoid delayed extubation and related complications, and shorten length of ICU and hospital stay, leading to improve the prognosis of patients [9-11, 17]. Coplin et al. found that $48 \%(29 / 60)$ of patients with GCS score $<8$ had delayed extubation compared with $10.5 \%$ (8/76) of patients with GCS $>8(P<0.05)$ [20]. Particularly interesting was the fact that there was almost no difference in consciousness on the day when the extubation criteria were met and the day of extubation in the delayed extubation patients. At the same time, the study also found that patients with swallow reflex and cough reflex disappeared or weakened could also extubated successfully. These findings challenge the conventional indicators of airway protection (such as swallow reflex, cough reflex, GCS score). These indicators which are not only used to evaluate airway protection ability but also commonly used by clinicians to assess the failure rate of noninvasive ventilation $[21,22]$. Therefore, so are these indicators still important for patients with brain injury? In this study, the median GCS score of NIV patients was 9 points, which was lower than the general criteria (GCS > 13). In 33 patients with noninvasive ventilation, only 4 patients failed in noninvasive ventilation, and 3 cases of them used the noninvasive ventilation for respiratory failure after extubation, for the preventive treatment of respiratory failure, noninvasive ventilation obviously has a good effect in this study [23].

Compared with NIV, tracheotomy is an invasive operation and also very common in ICU. At present, more and more ICU doctors can perform percutaneous tracheotomy beside the bed. Tracheotomy has many potential advantages, and it reduces the risk of self-extubate, airway injury, respiratory resistance, facilitating drainage of secretions, better tolerance, and less sedation and analgesia requirement [24]. McIntyre et al. first suggested that patients who need artificial airway more than 21 days should be considered tracheotomy [25]. And then, D'Amelio et al. found that early tracheotomy in patients with

Table 3 Primary and secondary outcomes of patients

\begin{tabular}{|c|c|c|c|}
\hline Variable & $\mathrm{NIV}(\mathrm{n}=33)$ & Tracheotomy $(n=44)$ & $P$ value \\
\hline Postoperative pulmonary infection, n(\%) & $18(54.5 \%)$ & $37(84.1 \%)$ & $0.005^{a}$ \\
\hline Atelectasis, n (\%) & $2(6.1 \%)$ & $5(11.4 \%)$ & 0.692 \\
\hline Mortality in ICU, n(\%) & $1(3.0 \%)$ & $6(8.0 \%)$ & 0.228 \\
\hline GCS score at ICU discharge & $12.0(13.0-14.0)$ & $10.0(8.0-12.0)$ & $<0.001^{\mathrm{b}}$ \\
\hline$\triangle \mathrm{GCS}$ score at ICU & $4.0(3.0-5.0)$ & $0.5(0.0-2.0)$ & $<0.001^{\mathrm{b}}$ \\
\hline Total mechanical ventilation time, hours (Median, IQR) & $218.0(142.0-294.5)$ & $195.0(127.3-372.3)$ & 0.658 \\
\hline Invasive mechanical ventilation time, hours (Median, IQR) & $123.0(89.5-218.0)$ & $195.0(127.3-372.3)$ & 0.005 \\
\hline ICU duration, days (Median, IQR) & $14.0(9.0-22.5)$ & $18.0(13.3-26.8)$ & 0.059 \\
\hline Hospital duration, days (Median, IQR) & $22.0(17.0-29.5)$ & $28.5(18.25-41.75)$ & 0.151 \\
\hline
\end{tabular}

Data are expressed as the median and interquartile ranges (IQR), or percentages. COPD Chronic Obstructive Pulmonary Disease, APACHE /I Acute Physiology and Chronic Health Evaluation; ICU intensive care unit, GCS Glasgow Coma Scale, $\triangle$ GCS score at ICU: GCS score difference between admission and discharge ICU; a: $P<0.05 ;$ b: $P<0.001$ 


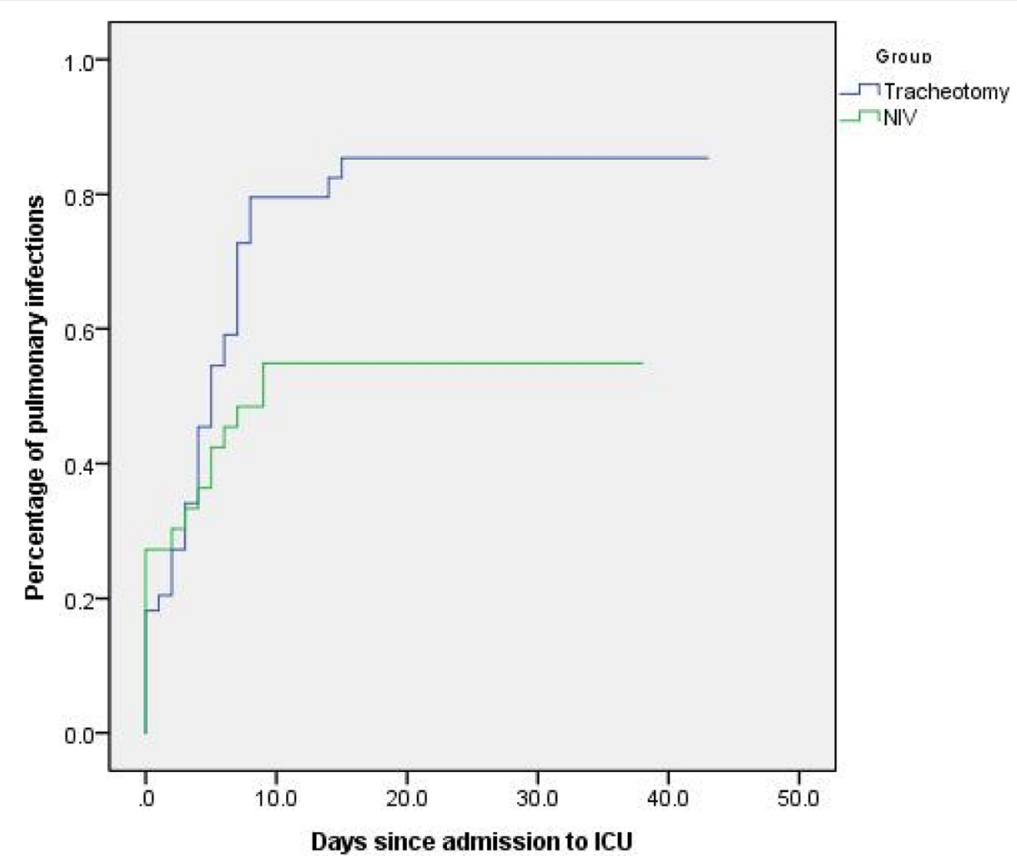

Fig. 1 Percentage of pulmonary infections since admission to ICU in the NIV and tracheotomy groups. $P<0.05$ by log-rank test

brain injury (mechanical ventilation days less than 7 days) can reduce the duration of mechanical ventilation, length of ICU and hospital stay [26]. Subsequently, a large RCT study demonstrated that early tracheotomy (6-8 days after mechanical ventilation) did not significantly reduce the incidence of ventilator-associated pneumonia, 28-day and one-year mortality, and time of hospital stay compared with later tracheotomy (13-15 days after mechanical ventilation) [27]. Therefore, there is no accepted conclusion about the appropriate timing and indication of tracheotomy in patients with brain injury, but the only fact which is generally accepted is that when the GCS score is still less than 8 points after 7 days of mechanical ventilation, early tracheotomy is recommended for patients pre estimate longer mechanical ventilation [28]. All of the patient enrolled in our study chose to undergo tracheotomy or NIV only after their craniocerebral state was stable, our ICU doctor will evaluate the patient's condition every day. If the patient's condition is stable, we will stop using sedation and discuss whether tracheotomy or NIV was undergone, so the GCS scores of the patients with tracheotomy in this study were all higher than or equal to 8 points, and $78 \%(47 / 60)$ of the patients underwent early tracheotomy (mechanical ventilation days $<7$ ). This may be the reason why the incidence of pulmonary infection, duration of invasive mechanical ventilation, time of stay in ICU and hospital in the tracheotomy group were higher than those in the NIV group. In addition, the risk factors of postoperative pulmonary infection in brain injury surgery patients included: older age, longer coma time, complicated with chronic underlying diseases, smoking history, tracheal intubation, tracheotomy, tracheotomy intubation for a long time, long hospitalization days, and irrational use of antibiotics and the like.

There are some limitations in this study, firstly, we cannot completely balance the bias caused by potential unknown confounding factors, for example, snoring, lingual drop, tracheal displacement, analgesic and sedative drug use. And most of all, NIV is a respiratory treatment influenced by several factors easily, and staff training is a key one. Medical workers with different clinical experience may have a different understanding of the clinical application of NIV [29]. What's more, because this study was a retrospective cohort study that was not a prospective randomized controlled trial, the baseline characteristics of the NIV and tracheotomy patients were not well balanced, for instance, although there was no significant statistical difference in GCS scores prior to NIV or tracheotomy between NIV and tracheotomy patients, the NIV group had a trend of a higher GCS score before NIV, which may cause selective bias in the results. Therefore, more comprehensive prospective studys with a larger sample size are necessary to explain these issues better, further explore the application of noninvasive ventilation and tracheotomy in patients with brain injury, and identify the better respiratory support and airway management methods and timing to maximize patient benefits. 


\section{Conclusion}

As far as we know, this is the first study investigating the impact of NIV and tracheotomy on the prognosis in critically ill mechanically ventilated neurosurgical patients. Compared with patients underwent tracheotomy, the patients who accepted NIV has a lower incidence of postoperative pulmonary infection, shorter duration of invasive mechanical ventilation, higher GCS score at discharge ICU, as well as significant GCS score difference between ICU admission and discharge. Researches about the impact of noninvasive ventilation and tracheotomy on the prognosis of neurosurgery patients are necessary in the future. Furthermore, the effect of NIV in those patients still requires more efforts.

\section{Abbreviations \\ APACHE II: Acute Physiology and Chronic Health Evaluation; ARDS: Acute respiratory distress syndrome; COPD: Chronic Obstructive Pulmonary Disease; CPIS: Ventilator associated pneumonia; GCS: Glasgow Coma Scale; ICU: Intensive Care Unit; IMV: Invasive mechanical ventilation; IQR: Interquartile ranges; MV: Mechanical Ventilation; NIV: Noninvasive ventilation; RCT: Randomized Controlled Trials; SCPIS: Simplified version of the clinical pulmonary infection score; SD: Standard deviation; VAP: Ventilator associated pneumonia}

\section{Acknowledgements}

We would like to thank all of the patients who participated in this study.

\section{Funding}

This work was supported by the "National Natural Science Foundation of China", Grant No.81701880 and No.8187081616.

\section{Availability of data and materials}

Data supporting the conclusions of this study are provided within the manuscript. Raw data is available from the corresponding author upon reasonable request.

\section{Authors' contributions}

ML D collected and analyzed the clinical data, as well as drafted the manuscript. YF Z, JY1, JY2, XL L and YK participated in the study design and helped to draft the manuscript. All authors read and approved the final manuscript.

\section{Ethics approval and consent to participate}

the West China Hospital of Sichuan University Biomedical Research Ethics Committee Approved this study (ID number: 2018-21).

\section{Consent for publication}

Not applicable.

\section{Competing interests}

The authors declare that they have no competing interests.

\section{Publisher's Note}

Springer Nature remains neutral with regard to jurisdictional claims in published maps and institutional affiliations.

Received: 4 December 2018 Accepted: 11 April 2019 Published online: 01 May 2019

\section{References}

1. Corrigan JD, Selassie AW, Orman JA. The epidemiology of traumatic brain injury. J Head Trauma Rehabil. 2010;25(2):72-80.

2. Marin JR, Weaver MD, Mannix RC. Burden of USA hospital charges for traumatic brain injury. Brain Inj. 2017;31(1):24-31.
3. Li Y, Zhou J, Chen F, Zhang J, Qiu J, Gu J. Epidemiology of traumatic brain injury older inpatients in Chinese military hospitals, 2001-2007. J clinical neuroscience : official journal of the Neurosurgical Society of Australasia. 2017:44:107-13.

4. Boles JM, Bion J, Connors A, Herridge M, Marsh B, Melot C, et al. Weaning from mechanical ventilation. Eur Respir J. 2007;29(5):1033-56.

5. Lee K, Rincon F. Pulmonary complications in patients with severe brain injury. Critical care research and practice. 2012;2012:207247.

6. Karanjia N, Nordquist D, Stevens R, Nyquist P. A clinical description of extubation failure in patients with primary brain injury. Neurocrit Care. 2011; 15(1):4-12.

7. dos Reis HF, Almeida ML, da Silva MF, Moreira JO, Rocha Mde S. Association between the rapid shallow breathing index and extubation success in patients with traumatic brain injury. Revista Brasileira de terapia intensiva. 2013;25(3):212-7.

8. Torres A, Gatell JM, Aznar E, el-Ebiary M, Puig de la Bellacasa J, Gonzalez J, et al. Re-intubation increases the risk of nosocomial pneumonia in patients needing mechanical ventilation. Am J Respir Crit Care Med. 1995;152(1):137-41.

9. Ferrer M, Sellares J, Valencia M, Carrillo A, Gonzalez G, Badia JR, et al. Noninvasive ventilation after extubation in hypercapnic patients with chronic respiratory disorders: randomised controlled trial. Lancet (London, England). 2009;374(9695):1082-8.

10. Glossop AJ, Shephard N, Bryden DC, Mills GH. Non-invasive ventilation for weaning, avoiding reintubation after extubation and in the postoperative period: a meta-analysis. Br J Anaesth. 2012;109(3):305-14.

11. Nava S, Gregoretti C, Fanfulla F, Squadrone E, Grassi M, Carlucci A, et al. Noninvasive ventilation to prevent respiratory failure after extubation in high-risk patients. Crit Care Med. 2005:33(11):2465-70.

12. Burns KE, Meade MO, Premij A, Adhikari NK. Noninvasive positive-pressure ventilation as a weaning strategy for intubated adults with respiratory failure. The Cochrane database of systematic reviews. 2013;(12):Cd004127.

13. Luna CM, Blanzaco D, Niederman MS, Matarucco W, Baredes NC, Desmery P, et al. Resolution of ventilator-associated pneumonia: prospective evaluation of the clinical pulmonary infection score as an early clinical predictor of outcome. Crit Care Med. 2003;31(3):676-82.

14. Kalil AC, Metersky ML, Klompas M, Muscedere J, Sweeney DA, Palmer LB, et al. Management of Adults with Hospital-acquired and Ventilatorassociated Pneumonia: 2016 clinical practice guidelines by the Infectious Diseases Society of America and the American Thoracic Society. Clinical infectious diseases : an official publication of the Infectious Diseases Society of America. 2016;63(5):e61-e111.

15. Guidelines for the management of adults with hospital-acquired, ventilatorassociated, and healthcare-associated pneumonia. Am J Respir Crit Care Med. 2005;171(4):388-416.

16. Lazaridis C, DeSantis SM, McLawhorn M, Krishna V. Liberation of neurosurgical patients from mechanical ventilation and tracheostomy in neurocritical care. J Crit Care. 2012;27(4):417.e1-8.

17. Girou E, Schortgen F, Delclaux C, Brun-Buisson C, Blot F, Lefort Y, et al. Association of noninvasive ventilation with nosocomial infections and survival in critically ill patients. Jama. 2000;284(18):2361-7.

18. Tobin MJ. Advances in mechanical ventilation. N Engl J Med. 2001;344(26): 1986-96.

19. Girou E, Brun-Buisson C, Taille S, Lemaire F, Brochard L. Secular trends in nosocomial infections and mortality associated with noninvasive ventilation in patients with exacerbation of COPD and pulmonary edema. Jama. 2003; 290(22):2985-91.

20. Coplin WM, Pierson DJ, Cooley KD, Newell DW, Rubenfeld GD. Implications of extubation delay in brain-injured patients meeting standard weaning criteria. Am J Respir Crit Care Med. 2000;161(5):1530-6.

21. Vagnarelli F, Marini M, Caretta G, Luca F, Biscottini E, Lavorgna A, et al. Noninvasive ventilation: general characteristics, indications, and review of the literature. Giornale italiano di cardiologia (2006). 2017;18(6):496-504.

22. McCredie VA, Ferguson ND, Pinto RL, Adhikari NK, Fowler RA, Chapman MG, et al. Airway management strategies for brain-injured patients meeting standard criteria to consider Extubation. A prospective cohort study. Annals Am Thoracic Society. 2017;14(1):85-93.

23. Ferrer M, Valencia M, Nicolas JM, Bernadich O, Badia JR, Torres A. Early noninvasive ventilation averts extubation failure in patients at risk: a randomized trial. Am J Respir Crit Care Med. 2006:173(2):164-70.

24. Griffiths J, Barber VS, Morgan L, Young JD. Systematic review and meta-analysis of studies of the timing of tracheostomy in adult patients undergoing artificial ventilation. BMJ (Clinical research ed). 2005;330(7502):1243. 
25. Maclntyre NR, Cook DJ, Ely EW Jr, Epstein SK, Fink JB, Heffner JE, et al. Evidence-based guidelines for weaning and discontinuing ventilatory support: a collective task force facilitated by the American College of Chest Physicians; the American Association for Respiratory Care; and the American College of Critical Care Medicine. Chest. 2001;120(6 Suppl):375s-95s.

26. D'Amelio LF, Hammond JS, Spain DA, Sutyak JP. Tracheostomy and percutaneous endoscopic gastrostomy in the management of the headinjured trauma patient. Am Surg. 1994;60(3):180-5.

27. Terragni PP, Antonelli M, Fumagalli R, Faggiano C, Berardino M, Pallavicini FB, et al. Early vs late tracheotomy for prevention of pneumonia in mechanically ventilated adult ICU patients: a randomized controlled trial. Jama. 2010;303(15):1483-9.

28. Koh WY, Lew TW, Chin NM, Wong MF. Tracheostomy in a neuro-intensive care setting: indications and timing. Anaesth Intensive Care. 1997;25(4):365-8.

29. Lopez-Campos JL, Garcia Polo C, Leon Jimenez A, Arnedillo A, GonzalezMoya E, Fenandez Berni JJ. Staff training influence on non-invasive ventilation outcome for acute hypercapnic respiratory failure. Monaldi archives for chest disease =Archivio Monaldi per le malattie del torace. 2006;65(3):145-51.

Ready to submit your research? Choose BMC and benefit from:

- fast, convenient online submission

- thorough peer review by experienced researchers in your field

- rapid publication on acceptance

- support for research data, including large and complex data types

- gold Open Access which fosters wider collaboration and increased citations

- maximum visibility for your research: over $100 \mathrm{M}$ website views per year

At $\mathrm{BMC}$, research is always in progress.

Learn more biomedcentral.com/submissions 